\title{
A IMPORTÂNCIA DAS AULAS PRÁTICAS NA PERSPECTIVA DE ALUNOS JOVENS E ADULTOS
}

\section{Mayara Cazadini Carlos ${ }^{1}$ \\ Lucyelen Costa Amorim ${ }^{2}$ \\ Adriana de Medeiros Marcolano Thebas ${ }^{3}$}

Resumo: A educação de jovens e adultos é uma modalidade de ensino que na maioria das vezes atende alunos que possuem compromissos diários e a rotina cansativa, fazendo com que haja um desinteresse em dar segmento aos estudos, e para recuperar o interesse desses alunos, é preciso diversificar a metodologia de ensino. Tendo como objetivo constatar a relevância que práticas pedagógicas possuem no processo de ensino-aprendizagem dos alunos jovens e adultos foi aplicado um questionário composto por nove perguntas objetivas em turmas do EJA de uma escola Estadual. Através dos resultados obtidos foi possível observar que a aula prática é um mecanismo facilitador do processo de ensino-aprendizagem para essa modalidade de ensino. Sendo assim, foi possível concluir que a aplicação de práticas pedagógicas diversificadas contribui para a aprendizagem dos alunos do EJA.

Palavras-chave: EJA; Aulas práticas; ensino-aprendizagem.

\footnotetext{
1 Ciências Biológicas/Instituto Federal do Espírito Santo/Campus-Alegre, Brasil. E-mail: may_cazadini@hotmail.com.

2 Ciências Biológicas/Instituto Federal do Espírito Santo/Campus-Alegre, Brasil. E-mail: lucyelen_amorim@hotmail.com.br.

${ }^{3}$ Letras/Faculdade de Filosofia Ciências e Letras de Alegre, Brasil. E-mail: marcolano20@hotmail.com.
} 